\title{
Rapid Climate Change and Climate Surprises A Look Back and Ahead
}

\section{BY GABRIEL M. FILIPPELLI AND CATHERINE SOUCH}

One of the great successes of scientific ocean drilling has been the identification of rapid and extreme climatechange events in oceanic sediments. The comprehensive coverage and analytical toolkit applied to these marine records has enabled us to understand some of the key drivers of climate change and to quantify the global impacts that climate change has had on the ocean and land. Sediment cores recovered from well-placed drilling sites contain climate-change records at human (i.e., millennial) timescales, in deep time like the Paleocene-Eocene Thermal Maximum (PETM), and in the more recent glacial/interglacial interval (both topics the subject of articles in this issue). These high-resolution records bring some promise that we can begin to understand how the Earth system responded to drivers of climate change in the past, and perhaps how these systems might respond in a world increasingly dominated by human-altered biogeochemical cycles. Hope for an integrated understanding of climate change gets even brighter when these marine records are combined with terrestrial and icecore data and oceanographic and atmo- spheric modeling to build coupled and, perhaps, predictive scenarios of past and future climate change.

In this paper we introduce some of the basic concepts behind climate change, including evidence for a human fingerprint on present and future climate, and examine the impact that climate change has on landscapes and the people inhabiting them. These examples show how an understanding of climatechange impacts, using a combination of marine, terrestrial, and ice records, may provide a window into future human responses. Perhaps the greatest lesson that we have learned from climate-focused scientific ocean drilling is that climate change is a geologic truism and thus any debate about the impact of humanproduced greenhouse gasses on climate should be informed by the dynamic nature of Earth's past climatic variability.

\section{CLIMATE-CHANGE DEBATE?}

"With all of the hysteria, all of the fear, all of the phony science, could it be that man-made global warming is the greatest hoax perpetrated on the American people? It sure sounds like it."

U.S. Senator James Inhofe (OK), 2003
The debate about the human fingerprint of climate change has evolved as research has focused more comprehensively on obtaining accurate records of climate parameters on a global scale. Some of the controversy revolved around the typical scientific scrutiny that we all bring to data analysis, with scientists presenting their results with all of the appropriate and reasonable cautions, and policymakers and the public "reading" these cautions as active debate and argument within the scientific community about global warming. As comprehensive global data sets have been scrutinized especially over the past decade, it has become clear that the atmosphere is warming, that polar temperatures are increasing rapidly, and that one main driver of this change is the increase in humanproduced greenhouse gasses. This scientific reality has now begun to permeate public and policy spheres, such that the quote by Senator Inhofe above perhaps reflects the last gasp for those opposed to the connection between human actions and climate change.

At this point, we are seeing a more cogent and productive "debate" about climate change circulating in the scientific 
community, with the simple, "Is it warming? Are humans the cause?" succumbing to a more sophisticated set of questions:

- At what rate is climate change occurring?

- What are the on-the-ground effects?

- How well can they be modeled?

- What are the risks/potentials for climate surprises?

The questions above require a different line of analysis to answer. One important approach is to carefully analyze recent data (the past $\sim 200$ years) to develop predictive tools for estimating continued climate change over the next several centuries. Although this approach is suited for global and data-intensive modeling and analysis, it falls short in assessing more abrupt or non-linear changes to climate, particularly those climate surprises related to shifts in oceanic heat and salt transport and landscape-atmosphere feedbacks. Furthermore, the narrow window of analysis provided by historical records of temperature, for example, means that only one short portion of the climate response can be observed, limiting our perspective of the dynamic interactions among Earth surfaces, ice, and the ocean and climate.

\section{DRIVERS OF RECENT CLIMATE} CHANGE

The concentration of greenhouse gases (carbon dioxide, methane, water vapor) in our atmosphere correlates closely with surface temperatures, revealing the role of the hydrologic cycle and the carbon cycle in defining climatic state and driving climate change. Perhaps the most striking aspect of the increase in the concentration of atmospheric carbon dioxide, with direct measurements pub- lished since the late 1950s (Figure 1a), is simply that it is occurring now, and can be measured at high precision. This increase is due to the addition of carbon dioxide to the atmosphere from human activities, mainly the combustion of fossil fuels, with the sharp seasonal wiggles reflecting the "breathing" of northern hemisphere biomass (low carbon dioxide in the spring/summer due to photosynthetic storage in leaves and plant matter, and high carbon dioxide in fall/winter as biomass dies and respiration dominates). How high will atmospheric carbon dioxide go in the future? This figure will depend on rates of fossil-fuel combustion as well as several potential feedback processes (both positive and negative), but we can with some confidence expect to see the value reach about $560 \mathrm{ppm}$ by the end of this century-effectively a doubling of atmospheric carbon dioxide content from the pre-industrial level. The geologic record indicates that such a level has not occurred on Earth for millions of years. What impact will such an increase of carbon dioxide have on climate and landscapes, and as a consequence on humans? This question is best examined through an understanding of longer-term variations in climate drivers as well as some examples of how sensitive landscapes and populations have been to even subtle climate change.

\section{DRIVERS OF PAST CLIMATE CHANGE}

Longer-term drivers of climate change over the past several million years arise from the interplay between orbital variations and Earth system feedbacks. Earth system feedbacks are the complex web of relationships among the geosphere, hydrosphere, and biosphere that has resulted in Earth remaining a habitable planet for about 4 billions years, even in the face of an ever-brightening Sun and periodic events like a global Ice Age about 600 million years ago and many catastrophic asteroid impacts though time. Orbital variations are the periodic changes in net solar insolation (and the timing of these changes) related to Earth having an imperfect orbit around the Sun. These variations naturally lead to slightly warmer and slightly colder temperatures on Earth, an effect amplified by more significant changes in the carbon cycle due to these variations. This amplification by the carbon cycle is reflected in Earth's temperature record, with higher atmospheric carbon dioxide leading to higher temperatures during interglacial intervals and the opposite effect during glacial periods. The variations in atmospheric carbon dioxide are extreme, with glacial values typically around $180 \mathrm{ppm}$ and interglacial values peaking at about $300 \mathrm{ppm}$ (Figure 1b). These high interglacial values are nothing compared to those that existed during the time of the dinosaurs (roughly 1500 ppm; Berner and Kothavala, 2001), however, the global climate state was much different then, and global average temperatures were certainly much higher to allow the global free reign of mostly cold-blooded organisms. Clear from this

Gabriel M. Filippelli (gfilippe@iupui.edu) is Professor and Chair, Department of Earth Sciences, Indiana University-Purdue University Indianapolis (IUPUI), Indianapolis, IN, USA. Catherine Souch is Head, Research and Higher Education Division, Royal Geographical Society (with IBG), London, UK. 

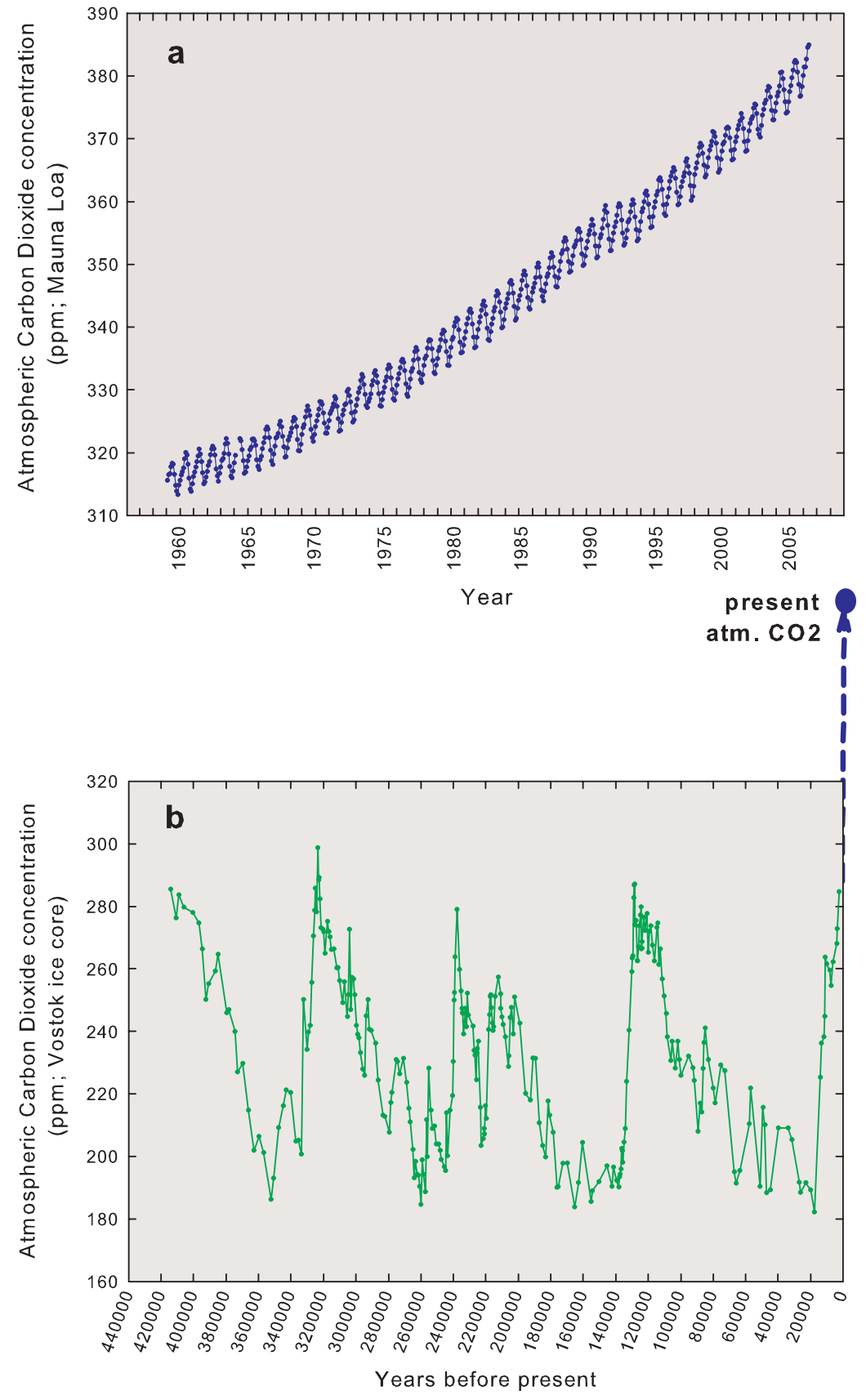

Figure 1. Records of atmospheric carbon dioxide concentrations. (a) Instrumental record from Mauna Loa Observatory, showing monthly data from 1959 until May 2006. Data from Keeling and Whorf (2005) with recent supplemental data from http://www.cmdl.noaa.gov/projects/src/web/trends/co2_mm_mlo. dat (last accessed June 13, 2006). The exponential increase in atmospheric carbon dioxide revealed by this record is the result of anthropogenic activities, chiefly the combustion of fossil fuels. (b) Ice-core record from Vostok, Antarcti$\mathrm{ca}$, showing glacial/interglacial fluctuation in atmospheric carbon dioxide (data from Barnola et al. [2003]) as well as the level at present. This record reveals the uniquely high value of present-day atmospheric carbon dioxide, indicating that modern values are neither part of a natural cycle nor have reached these levels in the recent geologic past. geologic record, however, is the high level that the concentration of atmospheric carbon dioxide has reached over the past 150 years. With current values above 380 ppm, we can say with confidence that atmospheric carbon dioxide has not approached this value for at least the past 420,000 years (Figure 1b), and perhaps not even the past several million.

\section{LESSONS FROM THE PAST,} FOR THE FUTURE

Given predicted warming under a scenario of enhanced concentrations of greenhouse gas, we have observed and will continue to expect significant highlatitude warming, melting polar ice, rising sea levels, and the consequent impacts on coastal stability. Another hypothesized consequence of global warming is increased tropical storm intensity, which together with rising sea levels might result in more risk for coastal populations (perhaps presaged by the impacts of Hurricane Katrina on New Orleans) (Patz et al., 2006). For purposes of planning, policy, and preparedness, it is useful to see how societies have responded to climate change in the past and to examine examples of the impacts of climate-change feedbacks in the past that might be similar to those we may experience in the future.

\section{Mayan Collapse}

The Classic Period of Mayan civilization was built on an unsustainable development model. The unsustainability was the result of rapid population growth and consequent food needs, widespread deforestation, and an agricultural system based on rainfall irrigation. The acme 
of the Mayan civilization was poised on the brink of massive failure because of the conditions above and one other factor that the Mayans could not have predicted - they flourished during an especially wet period, the result of a transient excursion of the Intertropical Convergence Zone (ITCZ). Lake sediment and ocean records (recovered during Ocean Drilling Program [ODP] Leg 165) (Figure 2a) reveal the rest of the story. As climate in Central America became more arid due to a shift in the ITCZ (Figure 2b) (Hodell et al., 1995; deMenocal, 2001; Haug et al., 2001), the rains expected to irrigate crops never arrived. This interpretation is based on both the sulfate record of aridity from a proximal terrestrial lake in the Yucatan Peninsula (Hodell et al., 1995) as well as a geochemical profile from ODP cores in a down-stream setting-the anoxic Cariaco Basin (Figure 2a) (Haug et al., 2001). This anoxic marine basin provides stratigraphic resolution high enough to match the local lake records, and provides a more regional support for aridification related to ITCZ excursions. With poor crop yields, no infrastructure for irrigation by ground or surface water sources, a soil nutrient bank depleted by deforestation and soil loss, and a large population, the Mayans were faced with widespread famine. If the Mayans had had in their hands the lake and marine records of natural climate variation, they might have planned their infrastructure to protect against the inevitable shift in the ITCZ and resultant drier conditions. The same might unfortunately be said in 2500 B.C. about societies thriving unsustainably in the $20^{\text {th }}$ and $21^{\text {st }}$ centuries.
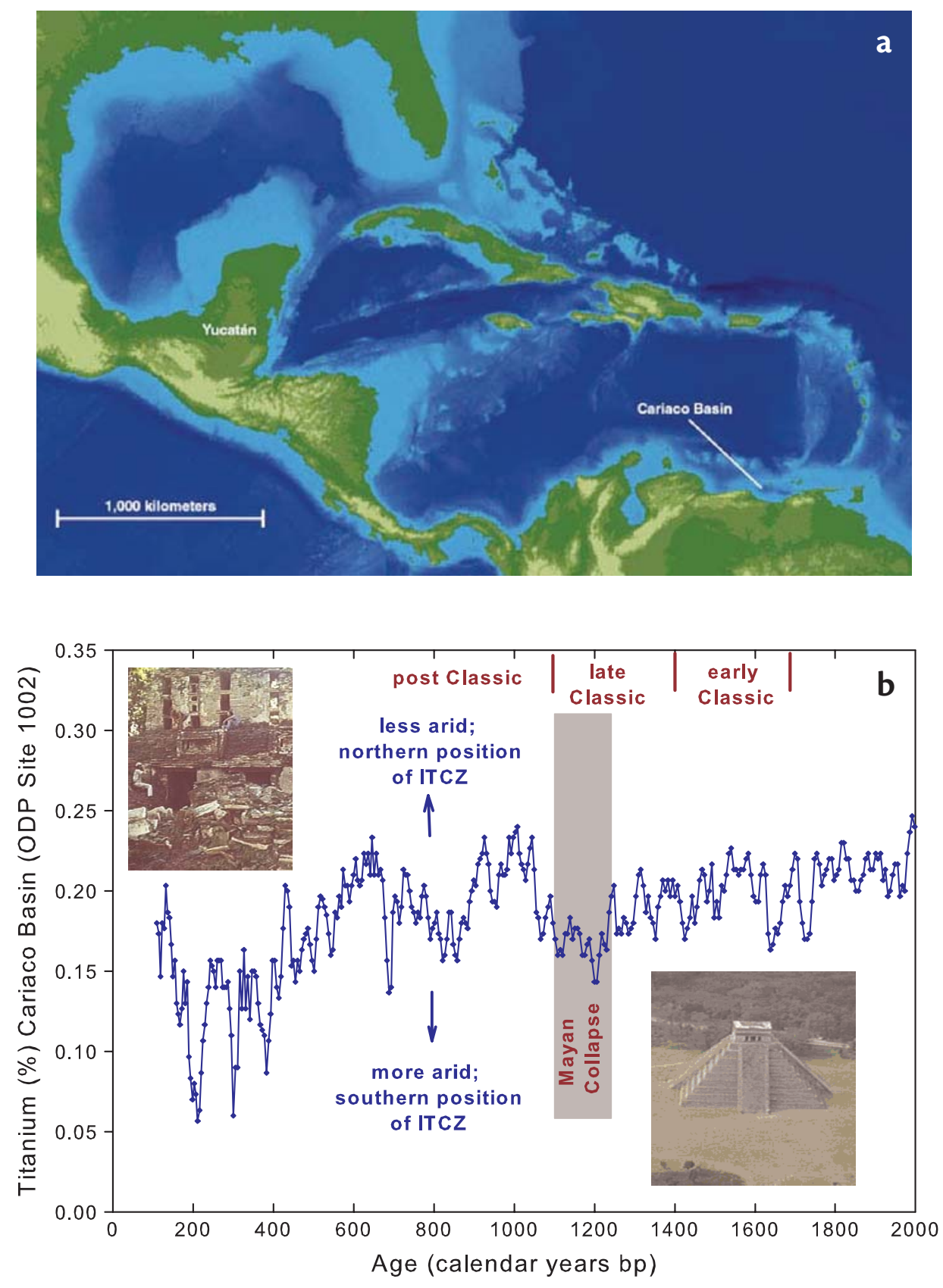

Figure 2. Scientific ocean drilling records of late Holocene climate change in the Caribbean were recovered from ODP Leg 165 with site locations in the Cariaco Basin. (a) This setting provided a high-resolution record "downstream" of the Yucatán Peninsula. (b) Titanium record of precipitation in the Cariaco Basin (from Haug et al. [2001]), interpreted to reflect precipitation in the Yucatán driven by natural variations in the position of the Intertropical Convergence Zone (ITCZ). The low values in the late Classic Maya period indicate more arid conditions in the Yucatán as the ITCZ swung southward. Along with poor soil management and overpopulation, the aridity and resultant lower crop yields (predominantly maize) for a population that did not have the infrastructure for artificial irrigation likely contributed to the collapse of the Mayan Civilization. 


\section{Holocene Climate Change-}

\section{The 8,200 ybp Cold Event}

Beyond the subtle changes in rainfall that can bring a civilization to its knees, other climatic variations have occurred in the recent past that could, in fact, be a model for understanding and preparing for climate "surprises" in the future. Perhaps most newsworthy of these is a cold event that occurred about 8,200 years ago.

This event was popularized by the movie "The Day After Tomorrow." The movie begins at a scientific conference where the hero (a paleoclimatologist, naturally) displays a paleo-record of the 8,200-year cold event and predicts the Hollywoodinflated climatic gloom and doom that dominates the rest of the movie. Regardless, that initial bit is real, and the event provides insight into what we now recognize as a very widespread climate surprise driven by a rather subtle change in the surface circulation of the North Atlantic Ocean. Many oceanographers suggest that this same scenario might occur in the near future. The production of deep water in the North Atlantic Ocean sets the heat balance in northern Europe and, perhaps, in much of the northern hemisphere. Decreases in the rate of deep-water formation is one expected outcome of enhanced freshwater input to the North Atlantic due to melting ice and changes in regional precipitation predicted in global-warming scenarios. Such a decrease in deep-water formation would be temporary (until substantial ice melting is complete), but a plausible outcome is significant cooling in Europe and the North Atlantic region in general (although some debate exists about the net thermal impact of deep-water production in this region) (see Rahmstorf et al., 2005; Schiermeier, 2006).

The impacts of such a climate "sur-

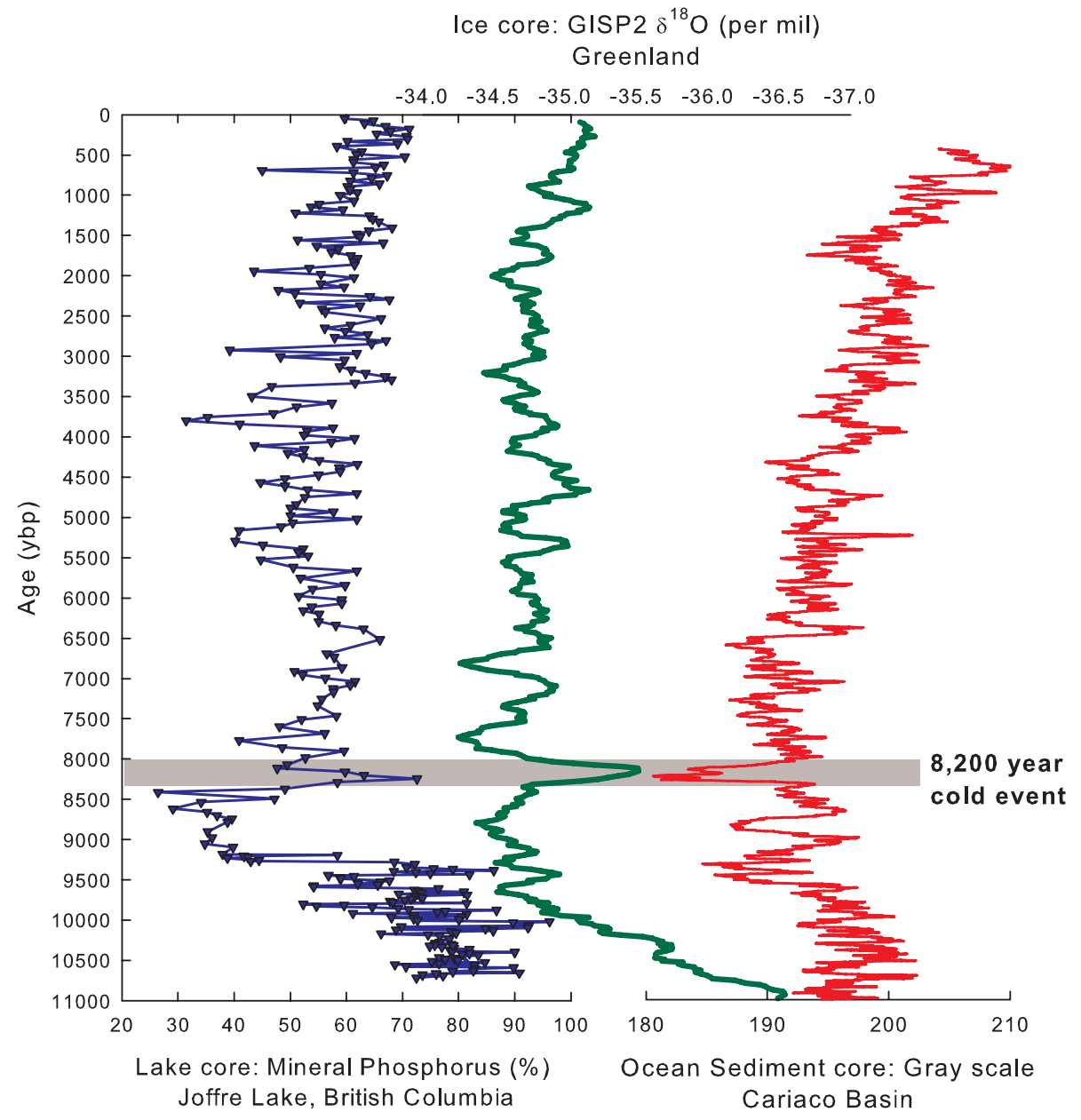

Figure 3. Mineral phosphorus (as a fraction of total $P$, which includes organic and oxide components) for a lake sediment core from the Coast Mountains of British Columbia (blue line; Lower Joffre Lake; data from Filippelli et al. [2006]), GISP2 ice-core record of oxygen isotopic variation (green line; data from Cross [1997]), and Cariaco Basin record of gray-scale changes reflecting sediment source and composition (red line; data from Hughen et al. [1998]). The ice core record reveals the 8200-years before present (ybp) cold interval observed in the North Atlantic region, which is temporally consistent with a spike in mineral $\mathrm{P}$ related to the advance of up-valley glaciers in the Coast Mountains and a shift in wind and source patterns indicated by the marine sediment record from the Cariaco Basin. The phosphorus geochemical record reveals a rapid shift toward a greater proportion of mineral phosphorus, suggesting that glacigenic sedimentation increased and that the soil nutrient status of the landscape, related to soil development, also changed. Thus, the marine, terrestrial, and ice-core records of the 8200-ybp cold event collectively reveal the rapidity, global extent, and impact of this climatic perturbation. These event characteristics are particularly troubling considering that some models predict ocean-circulation changes over the coming century similar to those that triggered the rapid climate change at $8200 \mathrm{ybp}$. 
prise" (surprising, because it could be rapid and the temperature effect is opposite of the expected global pattern) have been clarified substantially over the last decade from a combination of marine, ice, and lake core records. The Greenland Ice Sheet Project 2 (GISP2) ice-core record reveals substantial cooling in the North Atlantic region over a short 400-year window centering around 8,200 years before present (ybp) (Figure 3). This cooling may be the result of subtle changes in water balance and deep-water production (Alley and Mayewski, 1997). The ice-core record correlates strongly with ocean sediment core data from this same region (Bond et al., 2001). Recently, however, several studies have shown that the temperature effect was not restricted to the North Atlantic region and that it had profound effects on terrestrial landscapes. A marine sediment core from the Cariaco Basin, located in southern portion of the Caribbean Sea, reveals the distant effects of this ocean-circulation change on atmospheric circulation patterns and terrestrial paleoclimate (Figure 3) (Hughen et al., 1998). Additionally, lake sediment core records from far western Canada (Coast Mountains, British Columbia) reveal cooling and a rapid glacial readvance that is coupled with a change in soil nutrient status and ecosystem changes at 8,200 ybp (Figure 3) (Filippelli et al., 2006). These findings collectively support the hypothesis that this 8,200 ybp cold event was sufficient in magnitude to have had a hemispheric and perhaps even global impact (Alley and Mayewski, 1997). Albeit "temporary" on geologic timescales, one can imagine the catastrophic effects of several centuries of cooling on agricultural and energy industries, particularly as this would come at a time when societies are bracing for general warming. One strategy for minimizing these impacts is to carefully measure North Atlantic circulation patterns and develop more sophisticated models of circulation-temperature coupling that are tied to the geologic evidence left over from the 8,200-year event.

\section{SUMMARY}

Not if, but when and how much, are now the cogent questions related to climate change and global warming. We can learn important lessons about coupled Earth-system responses by looking carefully and comprehensively at past events revealed by scientific ocean drilling as well as lake and ice records. It is clear that earlier societies have been strongly impacted by climate change, and that those impacts could have been minimized by a greater understanding of climatic variability and better infrastructure planning. We are now in a position where scientific guidance based on the past can significantly inform policy for the present and outcomes for the future. This approach, coupled with modeling and risk assessment, will afford our global society the most flexibility and options when confronting global change.

\section{ACKNOWLEDGEMENTS}

Much of this work, and the work of references herein, is supported by the Ocean Drilling Program of the National Science Foundation. Additional support comes from NSF grants SBER 9911526 and OCE0452428. We would like to thank the input of reviewers Maureen Raymo, Karen Bice, and Arthur Mirsky. 四

\section{REFERENCES}

Alley, R.B., and P.A. Mayewski. 1997. Holocene climate instability: A prominent, widespread event $8200 \mathrm{yr}$ ago. Geology 25:483-486.

Barnola, J.-M., D. Raynaud, C. Lorius, and N.I. Barkov. 2003. Historical CO2 record from the Vostok ice core. In: Trends: A Compendium of Data on Global Change. U.S. Department of Energy, Oak Ridge National Laboratory, Carbon Dioxide Information Analysis Center, Oak Ridge, TN. [Online] Available at: http://cdiac.ornl.gov/trends/co2/vostok.htm [last accessed August 30, 2006].

Berner, R.A., and Z. Kothalava. 2001. GEOCARB III: A revised model of atmospheric $\mathrm{CO}_{2}$ over the Phanerozoic time. American Journal of Science 301:182-204.

Bond, G., B. Kromer, J. Beer, R. Muschler, M.N. Evans, W. Showers, S. Hoffmann, R. Lotti-Bond, I. Hajdas, and G. Bonani. 2001. Persistent solar influence on North Atlantic climate during the Holocene. $\mathrm{Na}$ ture 294:2,130-2,136.

Cross, M. compiler. 1997. Greenland summit ice cores. Boulder, CO National Snow and Ice Data Center in association with the World Data Center for Paleoclimatology at NOAA-NGDC, and the Institute of Arctic and Alpine Research. CD-ROM.

deMenocal, P.B. 2001. Cultural responses to climate change during the late Holocene. Science 292:667673.

Filippelli, G.M., C. Souch, B. Menounos, S. Slater-Atwater, T.A.J. Jull, and O. Slaymaker. 2006. Alpine lake records reveal the impact of climate and rapid climate change on the biogeochemical cycling of soil nutrients. Quaternary Research 66:158-166.

Haug, G.H., K.A. Hughen, D.M. Sigman, L.C. Peterson, and U. Röhl. 2001. Southward migration of the Intertropical Convergence Zone through the Holocene. Science 293:1,304-1,308.

Hodell, D.A., J.H. Curtis, and M. Brenner. 1995. Possible role of climate in the collapse of Classic Maya civilization. Nature 375:391-394.

Hughen, K.A., J.T. Overpeck, S.J. Lehman, M. Kashgarian, J. Southon, L.C. Peterson, R. Alley, and D.M. Sigman. 1998. Deglacial changes in Ocean Circulation from an extended radiocarbon calibration. Nature 391:65-68.

Keeling, C.D., and T.P. Whorf. 2005. Atmospheric CO2 records from sites in the SIO air sampling network. In: Trends: A Compendium of Data on Global Change. U.S. Department of Energy, Oak Ridge National Laboratory, Carbon Dioxide Information Analysis Center, Oak Ridge, TN. [Online] Available at: http://cdiac.ornl.gov/trends/co2/sio-keel.htm [last accessed August 30, 2006].

Patz, J.A., S.H. Olson, and A.L. Gray. 2006. Climate change, oceans, and human health. Oceanography 19(2):52-59.

Rahmstorf, S., M. Crucifix, A. Ganopolski, H. Goosse, I. Kamenkovich, R. Knutti, G. Lohmann, R. March, L.A. Mysak, Z. Wang, and A.J. Weaver. 2005. Thermohaline circulation hysteresis: A model intercomparison. Geophysical Research Letters 32:L23605, doi:10.1029/2005GL023655.

Schiermeier, Q. 2006. Climate change: A sea change. Nature 439:256-260. 